\title{
Urban perception and the Detective figure in Bleak House by Charles Dickens: The Labyrinth
}

\author{
Sana Ayed Chebil
}

Faculty of Arts and Humanities, Sousse, Tunisia

Received: 06 Nov 2021; Received in revised form: 14 Dec 2021; Accepted: 23 Dec 2021; Available online: 31 Dec 2021 (C)2021 The Author(s). Published by Infogain Publication. This is an open access article under the CC BY license (https://creativecommons.org/licenses/by/4.0/).

\begin{abstract}
Modern critics and theorists on urban vision insist that the city is 'a text' that can be read in a variety of ways to represent its complexity and 'unreadability'. The city in most theoretical frameworks is explored according to approaches that identify it as a text read by many types of readers. Twentiethcentury cultural theorist Michel de Certeau, for instance, tries to use the modernist lens through which the city is viewed as a space that can be interpreted according to two urban subjects: the "voyeur" and the "pedestrian". According to him, as many critics assume, the urban space, particularly the city, can be viewed according to two main positions: 'views from above' and 'views from below'. In the novel under study, Bleak House by Charles Dickens, the detective is represented as 'the reader' or producer of the city, the reader whose views of the city from 'above' and 'below' represent the labyrinthine structure of the Victorian city. The first part of this article attempts to represent the views of the city in two opposite directions: the views 'from above' and the views 'from below'. This paper depends on the figure of the detective who can be categorized as the 'voyeur,' the viewer and 'pedestrian' to map the discourse of the labyrinthine and invisible Victorian city.
\end{abstract}

Keywords - city, text, view from above, view from below, labyrinth.

\section{INTRODUCTION}

The Victorian era was a period in history in which almost everything was categorized by its disorder, lack of stability, and meaning (James 86-87). Shires refers to this destabilization as the main characteristic of the era, suggesting that the Victorian era is characterized by ambiguity and uncertainty, including relations between Man and God (14).

Critics of visual culture in the nineteenth-century era stress their focus on urbanization. De Certeau, for instance, argues that this age is characterized by "a cancerous growth of vision" (xxi). Kate Flint refers to the ambivalence and uncertainty associated with the Victorian era, assuming that this era is an era of invisibility, darkness, and ambiguity. In this respect, Flint further assumes that Victorians are blinded by the sickness of the 'eye' and are interested in "the problems of interpreting what they saw" (Flint 1). Flint also refers to the hidden meaning of the "Victorian surface" that is characterized by illegibility (21).

As the goal of this article is to represent the darkness and invisibility of the modern city, it is important to provide readers with the modern theories of spatial narratives. In fact, the Victorian era was the era of direct contact between the city and urban subject, the contact that was literally represented as chaotic. The detective figure, for instance, is the subject who often views and produces the city: the city that is produced by him as an urban walker or viewer (Baumgarten117).

The representations of the Victorian city are the products of 'the viewer' and 'the walker'. Modern theories introduce two positions through which the city can be represented and analyzed in Victorian literature. As the title of this article suggests, the city calls for the producer of the city (the city viewer and walker). It provides readers with a chain of representations made by various perspectives. The 'above/below views' are the main types 
of perceptions through which readers notice the ambiguity of the Victorian city and its visual experience. This duality is the area throughout the article through which the city can be examined and interpreted.

To begin with, drawing on De Certeau's theory, it is important to examine the 'up' and 'down' duality which creates two different ways of perceptions; "the map and the tour". According to him, 'the map' is produced by the eye, while the tour follows the logic of movement: While 'the map' creates a picture, an image, 'the tour' forms movements (de Certeau 119). He differentiates between two urban spectators of the city. The view of the city 'from above' categorizes its viewers as readers of the urban space; however, its walkers below are the city's 'writers' (93). According to him, 'walking' is crucial to the perception and production of the city. Unlike the "voyeur," who is the viewer, the urban observer on high, is the "walker" who has a direct contact with the streets and crowds. The former is located within the category of the 'seer', the observer who controls the city from above; the latter sets up a direct contact with the urban space (de Certeau 119). Both produce the horrific side of the city; its infinite structure, invisibility, and unknowlability. Accordingly, walkers are the urban subjects who follow "the thicks and thins of an urban "text"" (93); however, they are unable to 'read' and produce a clear meaning. To conclude, the two types of urban subjects participate in the horrific production of the urban space, "making the legible illegible" and representing the gloomiest characteristics of the city that cannot be introduced without mentioning the important roles that "the pedestrian or street-level viewers" play (Ridenhour 82).

\section{ANALYSIS OF BLEAK HOUSE}

This article introduces the two maps through which the mysterious city in the novel under study can be represented. Bleak House is mainly about visual perception (Gomel 50). The latter can be examined according to, as seen above, the 'viewer' and 'walker'. The following sections of this article will represent the city as a horrific space that can be perceived 'horizontally' and 'vertically'. As Gomel assumes, "London is seen both vertically and horizontally from "above" by the omniscient narrator and from "below" by Esther herself" (50). In what follows, this paper attempts to demonstrate the detective figure that performs the roles of the viewer and walker, the roles that offer the images of horrific and labyrinthine city.

\section{1-The Viewer}

In Dickens's novels, the city is a place of invisibility and gloominess. In Victorian literature, cities are represented "as unreadable texts," that attempt to represent "the inscrutability and unknowability of modern urban life" (Johnson 458). Dickens introduces a further mode of nineteenth-century writing - 'the foggy panorama' (Byrely 107). The novel begins with the gloominess of urban fog, an invisible 'panoramic' view opening the novel: "Fog everywhere" (Dickens 1).

In the novel under study, the mysterious representation of the city, as many critics suggest, provide readers with 'a panoramic view' of the city introduced by the omniscient narrator. Indeed, he uses fog in order to emphasize the mysterious character of London (Byrely 107). The omniscient narrator is located within the category of the 'viewer'. The dark atmosphere is stressed by references to the urban fog. The literary representations of Victorian literature are the product of its viewers, spectators, and walkers who perceive and experience the city and in turn provide a gothic portrayal of the urban experience.

Dickens represents the city through the sense of visual perception which is based on 'foggy panorama' (Byrely 107) as the book's title, Bleak House, enhances readers' expectations about absence of visibility. He produces the gloomy image of London where people are lost. The novel depicts the invisible traits of city, which add to its gloomy atmosphere. As Grub assumes: "the city becomes unrealistic via the fog that obscures it..." (80). The fog blinds its viewers; therefore, the urban space "presents the act of seeing as troubled, limited, and problematic from the outset" (Rignall 14).

Writing about urban literature makes Dickens depend on panorama, locating the city immediately before its viewers, a method of representation that depends on visual perception (Byrely 107). The panoramic view leads to the "illusion" of having a mimetic representation of the city (Byrely 108). 'Foggy panorama' of Bleak House contributes to the representation of the invisible and unknown city (Byrely 107). Bleak house and its foggy scenes suggest that the early nineteenth-century city is not an easy space that can be seen, understood, and interpreted. Foggy panorama, that is the product of 'above view', to borrow de Certeau's phrase, also demonstrates the impossibility of grasping the meaning of the urban space (Nord 238). It offers a modern method of perceiving or observing the city, a mode of perception that provides ambiguity and invisibility.

The Victorian novel represents the contact between the detective and the city, a contact that is suggested by the rise of crime in urban streets. This literary figure provides readers with an examination of the horrific traits of the city. The city is represented as 'a text' that does include a hidden message, which is the labyrinth. This idea is introduced by many critics including Shires who assumes 
that a setting, namely the city, in literary outputs functions as a character or text represented by a number of observers, including the flậneur ${ }^{2}$ or the detective. Dickens's detective figure attempts to 'read' the crowd, the street, and other elements of the city that are literally produced as a 'text' (Hollington 86). The detective's representations of the city are based on various methods of looking at the city, while simultaneously offering a horrific image of urban life.

In Bleak House, Dickens depends on the detective figure who is one of the most powerful literary characters through which the ambiguity of the Victorian city can be represented. The gothic representation of the Victorian city highly relies on the direct contact between the city and this subject. In Bleak House, Bucket's vision of the urban space is depicted in various forms that cross the borders between the real and the imaginary world. The image of the mysterious city is created by his 'detached gaze' that transports the physical city into a mental one (Nord 238239). The urban gaze manifests itself in 'the bird's eye view' of the city that seems to invite readers and detectives to enter into an imaginary map of the urban space (Nord 238-239). To achieve a view of the city 'from above,' he "he mounts a high tower in his mind," yet he sees nothing. He sees "[m]any solitary figures [that] are creeping through the streets" (Dickens 824). Accordingly, Dickens describes this figure as the mythical figure 'a winged devil' (Dickens 94), who attempts to perceive the city, locating himself in places that intend to make the city visible (Nord 238). His fictional perception comes hand in hand with the modern theories, mainly the 'above' view discussed above.

Urban mystery is the product of visual images offered by the detective 'viewer' who represents the city by looking at it through "the tower" of his mind (Dickens 824). Bucket performs the role of the 'viewer' through which he alienates himself from the direct contact with urban space. This view represents urban mystery and unidentifiable figures, "a dark shapeless object," (Dickens 824) who are wholly unknowable. Dickens's "reading of the city" does not offer a finite view of the city (Shires xix). As demonstrated in the novel under study, the 'tower of his mind,' makes the city unknown and invisible. In this respect, this 'fictional' tower is the outcome of the mental picture that renders the urban space more complex and complicated.

In Bleak House, the detective looks for the criminal figure. He empowers his vision by the 'tower' that he attempts to climb in order to detect her, yet the crowd is mysterious as she remains 'blank' or invisible. He is unable to see its components and catch the criminal. The villain can disappear in the crowd. He looks "for identity (the missing body) in the city" (Sicher14). It is difficult for the detective to achieve knowlability and visibility as the criminal keeps wandering the city, unseen. Her unrecognized appearance stresses the strangeness of the city. She is "a gap in the urban text" (Brand 221). The Victorian era goes beyond the mimetic representation of the world. In this context, Wolfreys identifies the nineteenth-century city based on "a map of unknowability" (16).

There is a direct contact between the city and the detective as the latter applies the two modes of perceptions, which are viewing and walking the urban space. Bucket is described as an extraordinary figure. It is important to note that he resembles a 'camera': The detective is the main figure in urban literature, the figure who is "looking like a camera" (Thomas 138). Bucket is introduced as a Gothic character as he seems "to possess an unlimited number of eyes" to everyone he meets in the streets (Thomas 335). The gothic vision of the city is empowered by its portrayal from the 'tower' that he climbs in order to search for the criminal. He can observe the whole city from above; however, he cannot see its elements. 'Mounting the tower' leads to his distance from the mimetic and realist perception of the city. In other words, his perception leads to the imagined production or mental production of the city (Nord 238-239).

Bucket is a myth-producer of the city. Dickens alludes to myths in order to represent the complexity of the viewer's urban perception. He empowers Bucket when he offers him the role of the viewer from the 'tower' of his mind, the tower that alludes to the City of Babylon: the view of the city from above by the detective to capture criminals invokes literary allusions which, in turn stress the gothic atmosphere of London (Hollington 85-86). In this section, Dickens mixes elements of imagination, reality, and mythology to produce the gothic city. The 'fictional tower' that he climbs reminds readers of the tower of Babylon (Nord 238-239).

The main strategy of Dickens is turning the city into a mysterious space that cannot be easily viewed or understood. The latter represents the inability to create a finite image of the city when he observes the city "from above' (Nord 238-239). He sees a "dark shapeless object," (Dickens 824) the criminal figure he pursues. The city in Bleak House demonstrates that "urban life is too terrifying and opaque to be read" (Brand 90). More broadly than the focus on the visual impacts of the detective gaze, the urban context of Dickens's novel explains one of the most dramatic elements: its strategy of turning the city into a text. Bucket turns the crowd into a text and its elements 
into a mystery (Nord 2038). Within the urban landscape and in association with the criminal figure, the detective figure performs the similar strategy of turning his view into a text, yet the latter is accompanied by the inability to read someone's identity. The detective's perception of the city produces the lack of visibility, the gloomy and horrific urban environment.

The city is perceived as a dark place and is highly invisible. This invisibility is expressed through the viewer who wants to achieve visibility, between the urgent need to read the city and his inability solve the "problem of the unreadability of crime," which is at the heart of the detective and Urban Gothic genre (Thomas 38). The viewer and his 'tower' used to perceive city from the highest part of his mind to catch the criminals can only increase the mystery and the invisibility of the urban environment. It is "an all-embracing irony which questions the possibility of knowing anything for certain" (Rignall 14).

\section{2-The Detective as a Walker: 'From Below'}

The movement from the perception of the city 'from above,' to borrow De Certeau's words, to 'the street-level' vision will also create the images of the Victorian city as mysterious and infinite. This part will depend on the second urban subject: through the act of walking. The detective is interested in finding new ways of representing the city, highlighting the gloomiest side.

The main objective of this study in this part is to look for the strategies used by Dickens to produce the image of the city as a labyrinth. This image is in fact woven out of the detective's eyes and act of walking. In other word, it is an image born out of seeing and walking the city. There is an analogy between writing, reading, and walking the city in Bleak House through which the city can be represented. The labyrinthine structure of the city is not only the product of the viewer's perception of the city (Byrely 107), but also of its walker's. The detective's experience of walking in Bleak House's city captures de Certeau's theory of urban perception (Nord 238).In contrast to 'above view' of the city that no longer offers visibility and finite entity, the detective performs another role. He embodies the role of the transitional figure between viewer 'from above' and urban walker, from below' through his attached gaze. Dickens often seeks new modes for expressing the urban Gothic content. In Bleak House, the narrator allows $\mathrm{Mr}$ Bucket "pervade a vast number of houses, and strolls about infinity of streets" (803). The detective achieves a more direct encounter with the urban environment, a move that creates an alternation between two ways of relationship between the detective and urban space: that of connection and disconnection.
According to Dickens, both methods of perception practiced by the viewer and walker contribute to the creation of labyrinthine city, the image that is created by the detective's walking and re-walking in the city. Under this urban practice, the city becomes a labyrinth. This idea is illustrated implicitly when at the end of the novel, Esther is led by the detectives who go through "such a labyrinth of streets," the labyrinth that makes them forget "where [they] were" (Dickens 827).

Later on, the reader encounters the labyrinthine city which is clearly fashioned by the walker. The image of the labyrinthine city is also created by the detective's movements in the streets. According to de Certeau as Ridenhour assumes, "walkers in a city create a text with their routes, writing a narrative in which they participate as author and character" (109). The detective as a walker turns the novel's narrative into a text that is similar to labyrinths. In this respect, readers who follow the walker's activity are also trapped in the labyrinth. As result, the text itself becomes a labyrinth (Ridenhour 109). The labyrinthine city is the product of a 'woven text' that becomes more complicated by their walking, trapping the reader in a literal labyrinth (Ridenhour 109).

Drawing on modern critics' theories of urban perception, the detectives' representations of the city are located within the categories of 'viewing' and 'walking' the city. Walking the city puts the subject in a direct contact with the urban environment, particularly slums. This figure "makes darkness visible" providing readers with sketches about criminals and urban underground (Thomas 135). In this respect, the detective is no longer 'the viewer' of the city; however; being 'the walker' of the city, from his internal position, puts him in a direct contact with the urban space that helps the writer achieve the gothic taste: the image of labyrinthine city.

Dickens represents the threat of darkness when the detectives enter the city: "[a] villainous street, undrained, unventilated, deep in black mud" (Dickens 219). He introduces the urban labyrinth from the chaos and ruins of the city, mainly the absence of light, gloominess, and the polluted air perceived by walkers. The sentence, "can scarce believe his senses," lies at the heart of the field of Bucket's sensory experience when it comes to vision particularly (Tropp 73). The latter eliminates clarity and vision. As seen from the beginning of the novel, the detective's interaction with the city displays an inevitable problem with such perception. The city is represented as a space that embodies other forms of sensory perceptions.

As seen before, the experience of walking the city significantly involves a further form of labyrinth and invisibility: walking that leads to hell. Dickens alludes to 
other texts. The image of a maze-like city exemplifies how walking the urban space has a relation with older texts. Dickens assumes that the detectives "feel as if he were going, every moment deeper down, into the infernal gulf" (119). Accordingly, the quote serves to illustrate the hellish characteristic of the city. Dickens associates the urban spectators walking the labyrinthine streets with a literary image, that of the spectators walking in "Dante's Inferno" (Tropp 74). Dickens uses urban perception, mainly walking the city, to represent the nightmarish city. The words borrowed are suggestive of the theme of hell that can often be represented through the walker's urban perception. He uses the 'hellish imagery' to represent the nightmarish city (Tropp 74). The phrase "infernal gulf" comes from Dante's Inferno (Tropp 74). This demonstrates that the detectives who perform the role of urban walkers render the city visible as a kind of hell. It is the detective "as guide to the urban Hell which is the most relevant use of the Gothic pattern to expose the urban underworld of Victorian culture" (Tropp 74).

\section{CONCLUSION}

The notion of 'the city as a text' is present in different literary works and discussed by many critics and theorists in the nineteenth-century era. Particularly, the conception of the city expects different readers and various ways of representations. The representation of the city finds its origins in methods of mapping and observing the city through visual experience. There are various strategies for reading the nineteenth-century city. One specific way of representing the city is the 'panorama', practiced by the omniscient narrator or the detective, or from the other charters who encounter the city.

Bleak House can be seen as, as many critics maintain, Dickens's attempt to produce readers of the city, readers who reveal the complicated urban experience. Accordingly, several characters in the novel under study participate in this activity throughout the novel, a process underwent by urban spectators. The detectives are certainly engaged in reading the city. This article also demonstrates how the novel is abundant with urban invisibility, absence of clarity, or blindness that further urban characters struggle to uncover. Like the detectives, 'the acts of reading' performed by the 'viewers' or 'walkers' are accompanied with gaps and the absence of visibility, reflecting the urban anxieties of the era.

The panoramic view of the city is literally important to demonstrating urban mystery. Dickens's resistance to realistic portrayals of the urban environment is, therefore, accomplished by inability of urban 'panorama' to produce visibility. Dickens needs to introduce this inability in order to enhance the mysterious quality of the city, a perfect place that can hide criminals and shatter the detective's gaze. Therefore, the heavy fog denies any attempt at observing London clearly during day.

This article focuses on how the Victorian city is represented in terms of its invisibility and gloominess. In Bleak House, Dickens proposes two different ways of perceiving, experiencing, and representing the horrific aspects of the urban space. The city is represented through the combination of disconnection and involvement Through the various gazes of the detective and the different strategies performed, the detective attempts to find order in the chaotic city. However, because of the nature of the Victorian city and its incomprehensibility, be it 'above' or a ground-level, vision appears to be uncertain.

This article attempts to identify de Certeau's theory of 'the above-below views' of the city within the detective narrative. Dickens's city depends primarily on its viewers and walkers. The Gothic city, the invisible and the labyrinthine, is explored through the urban walkers' experience in the city. The urban figures resist viewing and reading. London is a gothic space, at 'above' or 'streetlevel'.

\section{ENDNOTES}

${ }^{1}$ The notion of the city as a text is present in different literary works discussed by many critics and theorists in the nineteenth-century era. The city as text, as "a secret text to be read" (Gilloch) requires a special kind of reader of modern metropolitan life.

${ }^{2}$ According to Benjamin, the flậneur is an urban figure who belongs to the male bourgeois class. This figure has many roles--detective, dandy, prostitute. (Gilloch 243).

\section{REFERENCES}

[1] Baumgarten, Murray. "Construction Identity in an Urban Setting: London, Dickens, and the Theatre of Homelessness". Victorian Urban Settings: Essays on the Nineteenth-Century Cityand its Contexts. Ed. Debra N, Mancoff and D. J. Trela. New York and London: Garland Publishing, INC, 1996. 74-89.

[2] Barthes, Roland. The Semiotic Challenge. Trans. Richard Howard. Berkeley, Los Angeles: University of California Press, 1994.

[3] Byerly, Alison. Are We There Yet? Virtual Travel and Victorian Realism. Ann Arbor: University of Michigan Press, 2012.

[4] De Certeau, Michel. The Practice of Everyday Life. Trans. S. Rendall. Berkeley: University Of California Press, 2011.

[5] Dickens, Charles. Bleak House. Wordsworth Classics. London: Wordsworth Editions Ltd, 1993. 
[6] Flint, Kate. The Victorians and the Visual Imagination. New York: Cambridge University Press, 2000.

[7] Gomel, Elana. Narrative Space and Time: Representing Impossible Topologies in Literature. New York and London: Routledge: Taylor and Francis Group, 2014.

[8] Grub, Susanne "Bleak London: (Neo) Dickensian Psychogeographies." English Topographies in Literature and Culture. Ed. Leiden: Boston, 2016. 74-93.

[9] Hollington, Michael. Dickens and the Grotesque. New York: Routledge, 1984.

[10] Nord, Deborah Epstein. Walking the Victorian Streets: Women, representation, and the City. Ithaca, NY: Cornell University Press, 1995.

[11] Ridenhour, Jamieson. In Darkest London: The Gothic Cityscape in Victorian Literature. Lanham: The Scarecrow Press, Inc, 2013.

[12] Rignall, John. Realist Fiction and the Strolling Spectator. Routledge: Taylor and Francis Group, 1992.

[13] Shires, Linda M. Perspectives: Modes of Viewing and Knowing in Nineteenth Century England. Columbus: Ohio State University Press, 2009.

[14] Thomas, Ronald R. Detective Fiction and the Rise of Forensic Science. Cambridge: Cambridge University Press, 2000.

[15] ---"Making Darkness Visible: Capturing the Criminal and Observing the Law in Victorian Photography and Detective Fiction". Victorian Literature and Victorian Visual Imagination. Ed. Carol T. Christ and John O. Jordan. Berkeley: University of CaliforniaPress. Berkeley: University of California Press, 1995. 134-169.

[16] Tropp, Martin. Images of Fear: How Horror Stories Helped Shape Modern Culture (1818-1918). London: Mc Farland, 2000.

[17] Walkowitz, Judith R. City of Dreadful Delight: Narratives of Sexual Danger in Late-Victorian London. Chicago: The University of Chicago Press, 1992.

[18] Wolfreys, Julian. Dickens's London: Perception, Subjectivity and Phenomenal Urban Multiplicity. Edinburgh: Edinburgh University Press, 2012. 